\title{
Influence of selective dispersion of MWCNT on electrical percolation of in-situ polymerized high-impact polystyrene/MWCNT nanocomposites
}

\author{
N. K. Shrivastava, S. Maiti, S. Suin, B. B. Khatua* \\ Materials Science Centre, Indian Institute of Technology, Kharagpur, Kharagpur-721302, India
}

Received 3 July 2013; accepted in revised form 28 August 2013

\begin{abstract}
This work demonstrates a simple method to develop highly conducting high impact polystyrene (HIPS)/multiwall carbon nanotube (MWCNT) nanocomposites through selective dispersion of MWCNT in HIPS matrix. The method involves in-situ polymerization of polybutadiene containing styrene monomer in the presence of HIPS beads and MWCNT. A significantly lower percolation threshold value than ever reported for HIPS/MWCNT systems was obtained using unmodified unaligned MWCNTs. With the increase in HIPS bead content (at a particular MWCNT loading) in the HIPS/MWCNT nanocomposites, the conductivity value was increased, suggesting that the presence of HIPS beads acted as excluded volume that decreased the percolation threshold. An increase in electrical conductivity from $1.91 \cdot 10^{-7}$ to $1.15 \cdot 10^{-5} \mathrm{~S} / \mathrm{cm}$ was evident, when the HIPS bead content was increased from 30 to $60 \mathrm{wt} \%$ at a constant loading of MWCNT (i.e. $0.6 \mathrm{wt} \%$ ). The morphological investigation of the HIPS/MWCNT nanocomposites revealed that, the MWCNTs were selectively dispersed in the in-situ polymerized HIPS region, outside the HIPS beads, which resulted in the lowering of the percolation threshold to a lower value of $0.54 \mathrm{wt} \%$. The morphology and electrical properties of the nanocomposites have been discussed in detail in the manuscript.
\end{abstract}

Keywords: nanocomposites, HIPS, percolation threshold, conductivity

\section{Introduction}

The conducting polymer composites, prepared through the incorporation of conducting filler into an insulating polymer matrix has become a field of growing interest for the last few decades, due to its immense applications in various fields, such as, electronics, aerospace, military, flexible electronics, electromagnetic interference (EMI) shielding, electrostatic dissipation and sensors [1,2]. The conducting behavior in the insulating polymer can be imposed by the incorporation of various conducting fillers such as carbon fibers [3], carbon black (CB) $[4,5]$, metallic fillers $[6,7]$ and carbon nanotubes (CNTs) $[8,9]$. The electrical and dielectric proper- ties of polymer/conducting filler composites depend mainly on the filler type, aspect ratio, size, filler loading and the state of dispersion of the filler.

A considerable amount of research effort has been devoted to develop polymer/CNT nanocomposites in the recent years due to the superior conductivity of CNTs over other conducting fillers, such as, $\mathrm{CB}$ [10-12]. Thus, a very high conductivity in the polymer/CNT nanocomposites can be achieved at very low loadings of CNTs. The efficient dispersion of CNT into the polymer matrix is very difficult to achieve due to the high van der Waals forces between the individual CNT [13]. The small size and large surface area of the CNT lead to such high van der

\footnotetext{
${ }^{*}$ Corresponding author, e-mail: khatuabb@matsc.iitkgp.ernet.in (C) BME-PT
} 
Waals forces of attraction, which restricts the dispersion of CNTs in polymer matrices. Hence, to achieve good dispersion of CNTs into polymer matrix, surface modification or functionalization of CNTs is carried out, which results in better adhesion of filler with the host polymer [14]. However, this sort of modification increases the surface defects of CNT, resulting in a decrease in its inherent conductivity $[15,16]$.

Various thermoplastics such as poly(methyl methacrylate) (PMMA) [17], polystyrene (PS) [18], polyethylene (PE) [19], polycarbonate (PC) [20], and others $[21,22]$ have been reported in the literature for the development of conducting polymer nanocomposites based on CNT. Among these, PS/CNT nanocomposites have extensively been studied in the previous reports. However, very little stress has been put on the other co-polymers of PS, such as, high impact polystyrene (HIPS). A few researchers have worked on co-polymers of PS. For instance, McClory et al. [23] studied the electrical conductivity of melt mixed HIPS/MWCNT nanocomposites and found an electrical conductivity of $\sim 10^{-6} \mathrm{~S} / \mathrm{cm}$ at $4 \mathrm{wt} \%$ loading of MWCNT in HIPS. Lee et al. [24] and Göldel et al. [25] studied the electrical properties of melt extruded SAN/MWCNT nanocomposites and found $\approx 4 \cdot 10^{-4}$ and $\approx 1 \cdot 10^{-4} \mathrm{~S} / \mathrm{cm}$ at 2 and $1.5 \mathrm{wt} \%$ MWCNT loadings, respectively. A DC conductivity of $\approx 10^{-2} \mathrm{~S} / \mathrm{cm}$ at $15 \mathrm{wt} \%$ of $\mathrm{CNT}$ loading in poly (styrene-co-butyl acrylate)/MWCNT nanocomposites was reported by Dufresne et al. [26]. Singh et al. [27] reported an electrical conductivity value of $\approx 1.27 \cdot 10^{-6} \mathrm{~S} / \mathrm{cm}$ in $(80 / 20 \mathrm{w} / \mathrm{w})$ ABS/PS blend at $0.64 \mathrm{wt} \%$ MWCNT loading.

A considerable research effort has been given towards the development of new methodology to reduce the percolation threshold of CNT in polymer matrix. Zhao et al. [28] reported the percolation threshold at $0.07 \mathrm{wt} \%$ of MWCNT in poly vinylidene fluoride (PVDF) by coating the PVDF spherical particles with MWCNTs through sonication. Mu et al. [29] developed a contiguous, cellular structure of SWCNT using SWCNT coated PS pellets followed by hot pressing. This method reduced the electrical percolation threshold compared to the composites with well-dispersed SWCNT. Liu and Grunlan [30] used nanoclay for inducing network of SWCNT in an epoxy matrix. They could reduce the percolation of SWCNT from 0.05 to $0.01 \mathrm{wt} \%$ by adding a small amount of clay. In summary, reports on PS and its copolymers indicate that, it is difficult to disperse the CNT in polymer matrix due to the inherent high melt viscosity of the base polymers. In order to avoid this, a solvent casting process can be used, which is again disadvantageous due to the presence of residual traces of solvent in the nanocomposites, and thus should be avoided. Moreover, the percolation threshold can be reduced to an exceptionally lower value through selective dispersion of MWCNT in the base matrix.

In the present study, we report a cost effective, straightforward method that involves selective dispersions of MWCNT in a continuous 3D network via exclusion of some volume of the base matrix. This method involves the polymerization of styrene in the presence of polybutadiene rubber followed by the introduction of the HIPS beads during the polymerization process. These beads can be considered as an 'excluded volume' in the nanocomposites which cannot take part in the generation of conductivity.

\section{Experimental}

\subsection{Materials details}

Synthesis grade styrene monomer, used in this study, was procured from Merck, Germany. Benzoyl peroxide (BPO) used as polymerization initiator, was purchased from Sigma-Aldrich Inc USA. Non cross-linked polybutadiene rubber (BR) (Buna CB 550 T) was supplied by LANXESS India Pvt. Ltd., Kolkata. General purpose high impact polystyrene (HIPS) copolymer was of commercial grade (grade SH-03;styrene with 1,3 butadiene polymer; styrene content $\approx 88 \% \mathrm{w} / \mathrm{w}$, specific gravity 1.03 1.05 at $25^{\circ} \mathrm{C}$; MFI $\approx 8.5 \mathrm{~g} / 10 \mathrm{~min}$ at $200^{\circ} \mathrm{C} / 5 \mathrm{~kg}$; average diameter of pellets $\approx 2.35 \mathrm{~mm}$ and length $\approx 2.70 \mathrm{~mm}$ ) was supplied by Supreme Petrochem Limited India. The MWCNT was industrial grade (NC 7000 series) supplied by Nanocyl S.A., Belgium. The MWCNT has an average diameter of $9.5 \mathrm{~mm}$ and length $1.5 \mu \mathrm{m}$, surface area $250 \sim$ $300 \mathrm{~m}^{2} / \mathrm{g}$, and $90 \%$ carbon purity. The MWCNT was used without any further chemical modification.

\subsection{Preparation of HIPS/MWCNT nanocomposites}

Styrene monomers were used after washing with $100 \mathrm{~mL}$ of $5 \mathrm{wt} \%$ aqueous $\mathrm{NaOH}$ solution for polymerization. Desired amount (0.29 g) of MWCNT was dispersed in $40 \mathrm{~mL}$ purified styrene monomer by 
ultrasonication for $2 \mathrm{~h}$ at room temperature. Then $4.32 \mathrm{gm}$ of butadiene rubber (BR) was dissolved in same styrene/MWCNT mixture. The styrene/BR/ MWCNT mixture was transferred to a specially designed $250 \mathrm{~mL}$ three-neck round-bottom flask with open head (like 6947 kettle, Borosil) connected with a condenser, a thermometer, and nitrogen gas inlet/outlet. Under magnetic stirring, required amount ( $1 \mathrm{wt} \%)$ of the BPO, as polymerization initiator, was added to the styrene/BR/MWCNT mixture. The reactor temperature was gradually increased to $\approx 85^{\circ} \mathrm{C}$ under constant stirring. During the progress of polymerization reaction (after $\approx 45 \mathrm{~min}$ of the reaction when styrene/BR/MWCNT mixture started developing very high viscosity), $23.45 \mathrm{~g}$ of commercial HIPS bead was added into the reactor. The reaction was continued for $5 \mathrm{~h}$ under nitrogen atmosphere with constant temperature and stirring. The HIPS/MWCNT nanocomposites thus obtained through in-situ bulk polymerization of HIPS/ MWCNT in presence of polymer beads was air dried and finally dried in hot air oven at $60^{\circ} \mathrm{C}$ for $24 \mathrm{~h}$. From the weight of the final product, the calculated loadings of CNT and HIPS bead in the HIPS/ MWCNT nanocomposites were 0.5 and $40 \mathrm{wt} \%$, respectively. The HIPS/MWCNT nanocomposites with higher CNT loading ( 0.7 and $1 \mathrm{wt} \%$ ) and higher amount of polymer bead $(50,60$, and $70 \mathrm{wt} \%$ ) were also prepared through the same polymerization route, by varying the amounts of styrene, MWCNT and the HIPS bead during the polymerization reaction. The schematic representation for the preparation of the nanocomposites is illustrated in Figure 1.

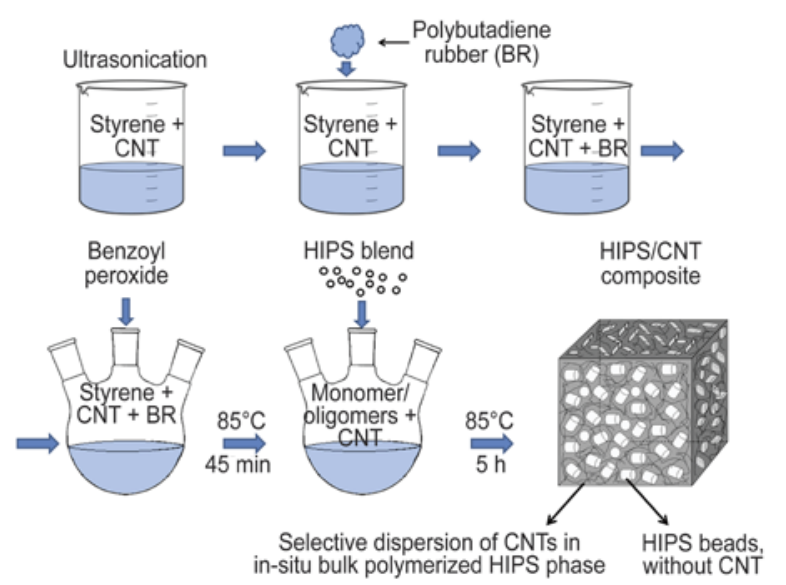

Figure 1. Schematic representation of the nanocomposites manufacturing process

\subsection{Molding of the HIPS/MWCNT nanocomposites}

Nanocomposites with various compositions of HIPS bead and MWCNT were compression molded at $210^{\circ} \mathrm{C}$ under constant pressure of $10 \mathrm{MPa} / \mathrm{cm}^{2}$. The molded parts were cooled naturally to room temperature and used for further characterization. Bulk polymerized HIPS having relatively low molecular weight and low melt viscosity (high MFI value) than the commercial HIPS bead is expected to flow easily inside the mold and thus, form the matrix phase though the content of HIPS bead is more in the nanocomposites.

\subsection{Characterization}

\subsubsection{Electrical conductivity}

Keithley sourcemeter Model 4200 (Keithley Instruments Inc., USA) with two-probe setup was used to measure the resistance $(R)$ by current-voltage $(I-V)$ measurement. DC conductivity was calculated by putting the values of $I-V$ measurement in Equation (1). The $I-V$ measurement was carried out in the range of +1 to $-1 \mathrm{~V}$. Each sample was tested for five times and the average was reported:

$\sigma_{\mathrm{DC}}=\frac{I L}{V A}$

where $\sigma_{\mathrm{DC}}$ is DC conductivity $I$ and $V$ are current and voltage, respectively. $L$ and $A$ represent the length and cross section area of the sample. Compression molded specimen with dimensions $30 \times 10 \times 3 \mathrm{~mm}^{3}$ were used for measurements. Before measurements, both sides of the nanocomposite were coated with silver paste. After that, both positive and negative electrode was put onto opposite sides of the sample.

The AC electrical conductivity of the nanocomposites (disc type sample with thickness $0.3 \mathrm{~cm}$ and area $1.88 \cdot 10^{-1} \mathrm{~cm}^{2}$ ) was determined using a computer controlled impedance analyzer (HIOKI 3532-50 LCR HiTESTER) on application of an alternating electric field across the sample cell in the frequency region of $42 \mathrm{~Hz}$ to $5 \mathrm{MHz}$. The parameters such as dielectric constant $\left(\varepsilon^{\prime}\right)$ and dielectric loss $\left(\varepsilon^{\prime \prime}\right)$ were found as a function of the frequency. The AC conductivity $\left(\sigma_{\mathrm{AC}}\right)$ was calculated from the dielectric data using Equation (2): 
$\sigma_{\mathrm{AC}}=\omega \varepsilon_{0} \varepsilon^{\prime} \tan \delta$

where $\omega=2 \pi f$ ( $f$ is the frequency), and $\varepsilon_{0}$ is the dielectric constant of the vacuum. The ratio of the imaginary to the real parts $\left(\varepsilon^{\prime \prime} / \varepsilon^{\prime}\right)$, known as the dissipation factor, is represented by $\tan \delta$, where $\delta$ is the angle between the voltage and the charging current. The dielectric constant $\left(\varepsilon^{\prime}\right)$ was determined by Equation (3):

$\varepsilon^{\prime}=\frac{C_{\mathrm{p}}}{C_{0}}$

where $C_{\mathrm{p}}$ is the capacitance of the sample (in parallel mode) $C_{0}$ is the capacitance of the cell. The value of $C_{0}$ was calculated using the Equation (4):

$C_{0}=\frac{\varepsilon_{0} A}{d}$

where $A$ and $d$ is the area and thickness of the sample respectively. $C_{\mathrm{p}}$ and $\tan \delta$ were obtained directly from the machine.

\subsubsection{Optical microscopy}

The distribution of MWCNT in the HIPS matrix was investigated by a high resolution optical microscope (HROM, Carl Zeiss Vision GmbH, Germany). The surface images were taken using a monochromatic light at different resolutions.

\subsubsection{Field emission scanning electron microscope (FESEM) study}

The phase morphology of the HIPS/MWCNT nanocomposites was studied by employing a field emission scanning electron microscope (FESEM, Carl Zeiss-SUPRA $^{\text {TM }} 40$ Germany), operated at an accelerating voltage of $100 \mathrm{kV}$. The samples were broken under liquid nitrogen atmosphere and cryo-fractured surface was coated with a thin layer of gold to avoid electrical charging.

\subsubsection{Transmission electron microscopy (TEM) analysis}

A high resolution transmission electron microscope (HRTEM, JEM-2100, JEOL, Japan) was used to study the dispersion of the MWCNT in the HIPS matrix, operating at an accelerating voltage of $200 \mathrm{kV}$. The HIPS/MWCNT nanocomposites sample was ultra-microtomed at $-50^{\circ} \mathrm{C}$ with a thickness of $100 \mathrm{~nm}$. Since the CNT has much higher electron density than the polymers, no staining was required and it appeared darker in the TEM images.

\section{Results and discussion \\ 3.1. Morphology}

The morphological analysis of the nanocomposite was done by capturing the optical micrographs and the findings were finally verified through the FESEM and TEM analysis. The optical micrograph, TEM image, FESEM image of the nanocomposites with $0.6 \mathrm{wt} \%$ MWCNT loading in the presence of $60 \mathrm{wt} \%$ HIPS beads are represented in Figure 2a-2f, respectively. As can be seen, the optical micrograph shows two distinct regions; a dispersed light region and relatively a dark continuous region (Figure $2 \mathrm{a}$ and 2b). An in depth analysis of the microstructure was done through the FESEM analysis. As observed, the CNTs were selectively concentrated in the continuous dark region while the remaining parts (dispersed light regions) were devoid of the considerable amount of CNT. From the above results we postulate that the CNT-rich continuous dark region is the bulk copolymerized HIPS phase, while the lighter region dispersed in the dark phase are the HIPS beads devoid of any CNT, as shown in the FESEM images. This consideration is reasonable due to the fact that when the HIPS beads were added to the reaction mixture, the polymerization has already progressed to the oligomeric stage. At this stage, it is difficult for the HIPS beads to swell as there was almost no monomer available in the reaction medium. Thus, we can conclude that the nanocomposites consist of two phases: one containing the bulk copolymerized HIPS along with the CNT while the other possessing the HIPS beads with discernible amount of CNT covering the surface.

The TEM images of the nanocomposites are represented in Figure 2e (low magnification) and $2 \mathrm{f}$ (high magnification). The presence of CNTs in selective regions was evident from the TEM image, supporting the result obtained from FESEM analysis. A better dispersion of the CNT in the selected regions of the matrix phase can easily be observed from the high magnification TEM micrograph. Moreover, the high magnification TEM image shows the clear separation between the individual CNTs, as was previously seen in the FESEM image. However, it was impossible to capture millimeter scale dimension HIPS beads in a single image; hence a portion 


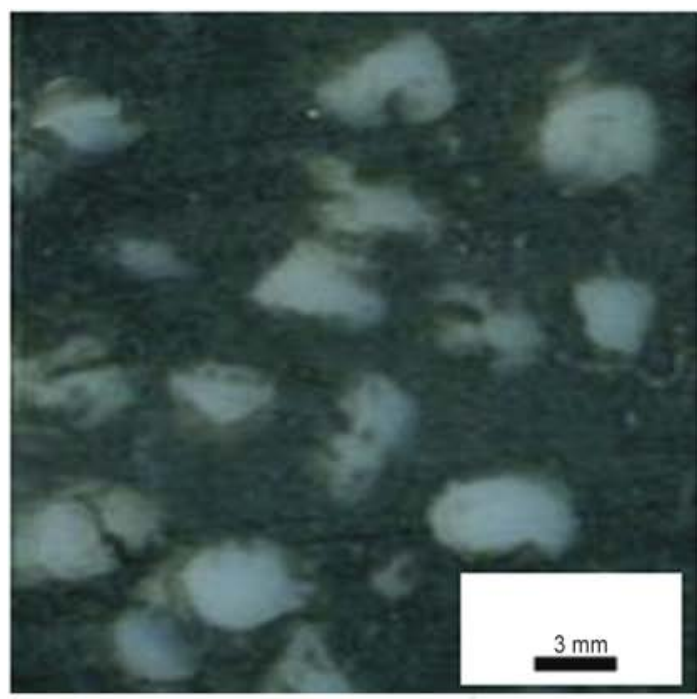

a)

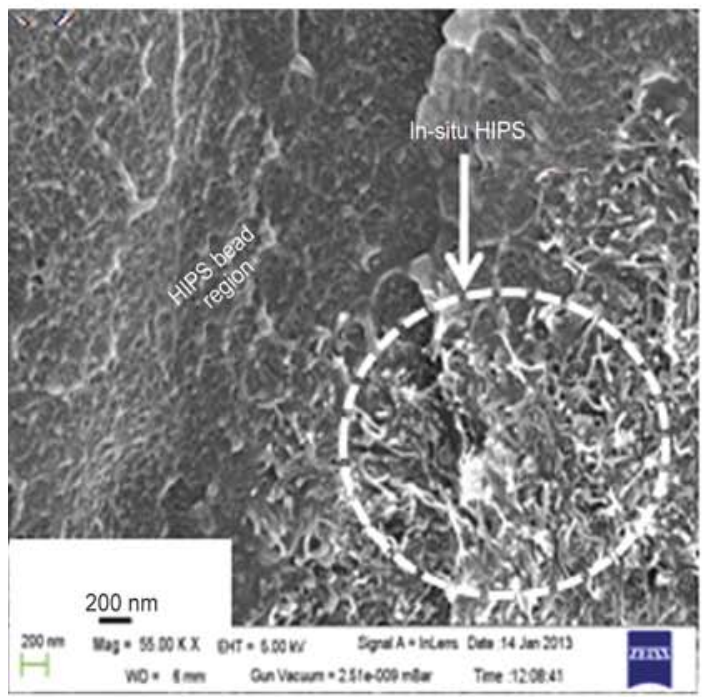

c)

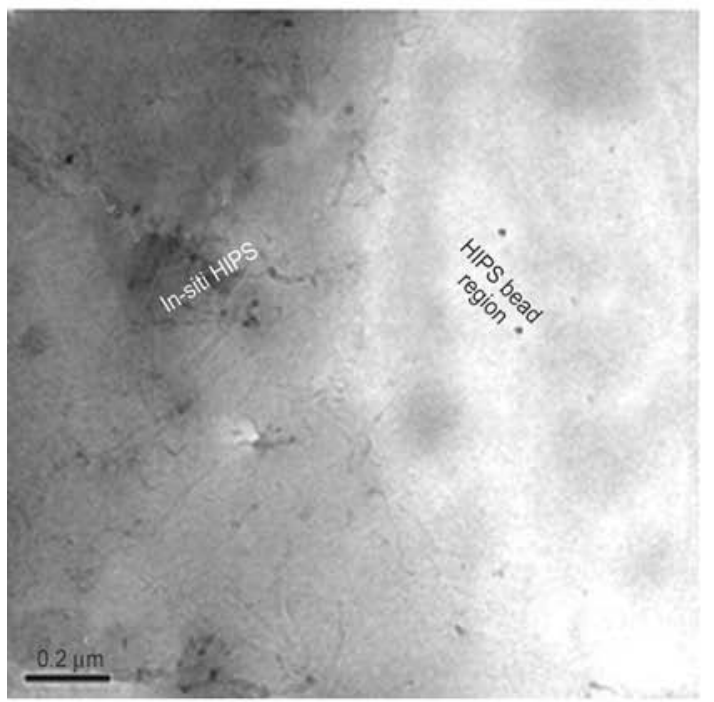

e)

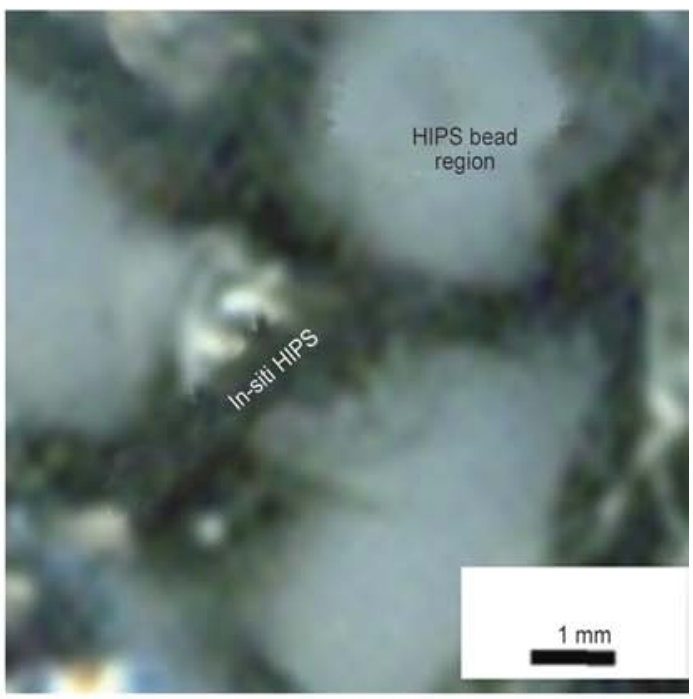

b)

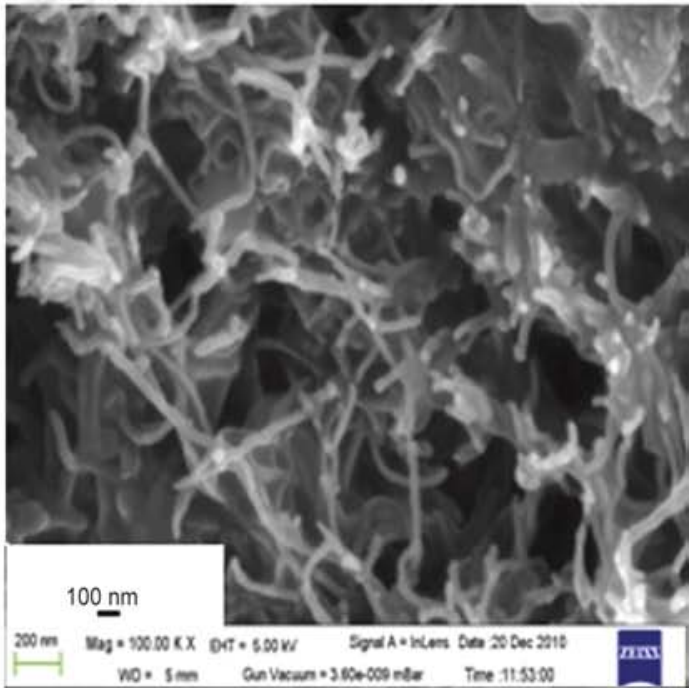

d)

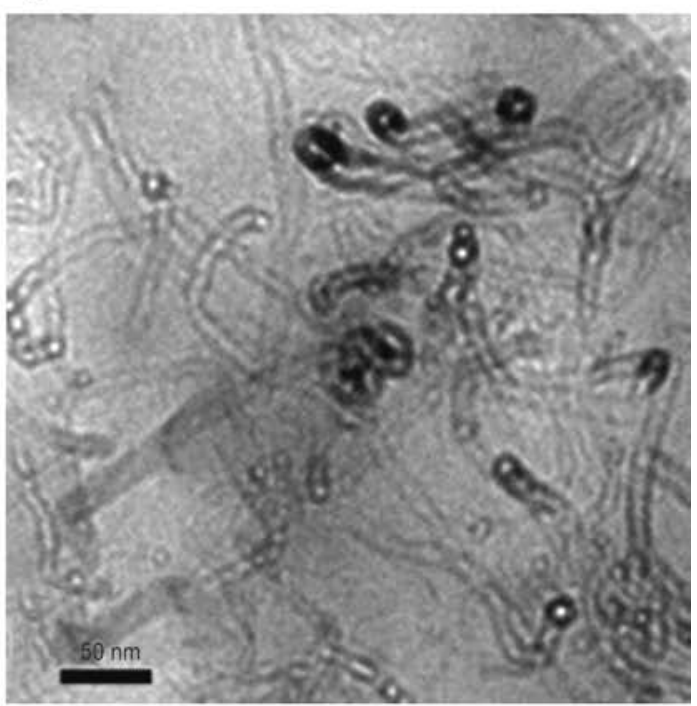

Figure 2. (a) low magnification (b) and high magnification optical micrograph, (c) low magnification and (d) high magnification FESEM micrograph, (e) low magnification and (f) high magnification TEM micrographs of $0.6 \mathrm{wt} \%$ MWCNT $60 \mathrm{wt} \%$ HIPS bead containing nanocomposites 
of the beads could be captured. In both the low and high magnification images no clear phase separation was observed, as both the regions contained the same polymer. From the morphological analysis it can be concluded that, the CNT forms a continuous network structure in the in-situ copolymerized HIPS regions, leaving the HIPS beads free of any CNT dispersion. This CNT free region acts as 'excluded volume' with negligible penetration of the CNT into the bead region that enhanced an effective concentration of the CNT in the nanocomposites. This facilitates the probability of the formation of more number of conducting paths throughout the nanocomposites.

\subsection{Electrical properties}

Figure 3 shows the effect of HIPS beads on the electrical conductivity of HIPS/MWCNT composite at room temperature. The conductivity of the composite increases with increasing the bead loading up to $60 \mathrm{wt} \%$. It is noteworthy that the electrical conductivity of the composite containing $0.6 \mathrm{wt} \%$ of MWCNT and without any bead does not show any considerable change in electrical conductivity in comparison to pure HIPS (i.e. $\approx 10^{-11} \mathrm{~S} / \mathrm{cm}$ ). Surprisingly, addition of $30 \mathrm{wt} \%$ HIPS bead in nanocomposites at the same concentration of CNT loading shows a DC electrical conductivity of $1.91 \cdot 10^{-7} \mathrm{~S} / \mathrm{cm}$. We hypothesized that the effective concentration of the MWCNT increases in the in-situ copolymerized matrix phase of the composite in the presence of HIPS beads. It is considered that HIPS bead plays the role of the excluded volume in the nanocomposite where MWCNT fails to penetrate. Therefore in-situ copolymerized HIPS/HIPS beads nanocomposite

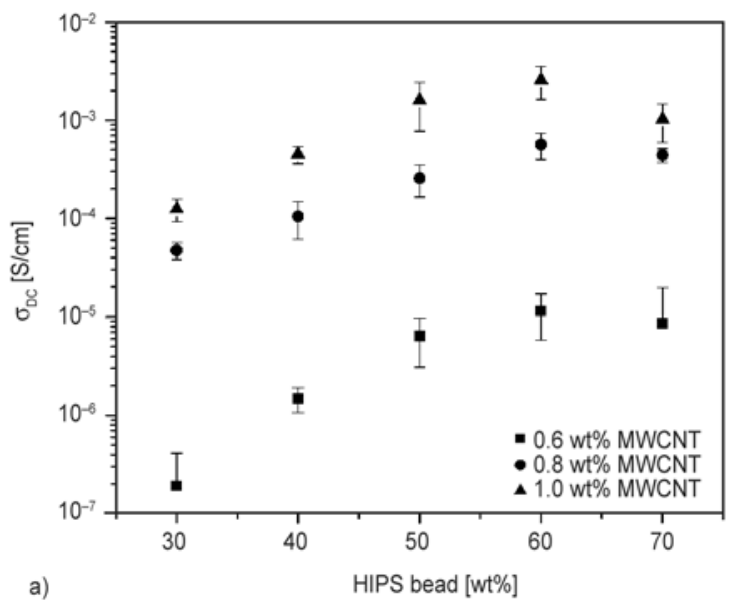

$(40 / 60 \mathrm{w} / \mathrm{w})$ with $0.6 \mathrm{wt} \%$ MWCNT loading in which theoretically calculated effective concentration of the MWCNT in in-situ polymerized phase is found to be $1.5 \mathrm{wt} \%$ (assuming all the CNT present in in-situ copolymerized HIPS phase). So it is expected that the composite, with $1.5 \mathrm{wt} \% \mathrm{CNT}$ loaded (without any HIPS bead) should exhibit comparable conductivity with composite containing $0.6 \mathrm{wt} \%$ MWCNT and $60 \mathrm{wt} \%$ HIPS bead.

To explore this assumption $1.5 \mathrm{wt} \%$ MWCNT loaded in-situ copolymerization HIPS without any bead was prepared and DC conductivity was found $8.76 \cdot 10^{-6} \mathrm{~S} / \mathrm{cm}$. It was found that the conductivity of $0.6 \mathrm{wt} \%$ MWCNT and $60 \mathrm{wt} \%$ HIPS bead loaded composite shows higher conductivity $\left(1.15 \cdot 10^{-5} \mathrm{~S} / \mathrm{cm}\right)$ than the composite containing $1.5 \mathrm{wt} \%$ MWCNT without any HIPS bead. This means that the effective concentration of the CNT in the polymerized phase of the bead containing composite is actually more than the calculated theoretical CNT concentration of $1.5 \mathrm{wt} \%$.

This increment of the conductivity may be due to diffusion of some styrene monomer and oligomer of CNT containing region to the HIPS bead which is evident by the swelling of the HIPS bead while mixing. Thus, a small reduction of the bulk polymerized HIPS in CNT containing region will occur which leads to the increment of the effective concentration of the CNT in polymerized HIPS phase.

Further, to verify this phenomenon we prepared a composite with small size HIPS bead (HIPS-s). Figure $3 \mathrm{~b}$ compares the electrical conductivity of the HIPS/MWCNT nanocomposites in the presence of HIPS bead and HIPS-s bead. Since diffusion (penetration of styrene monomer inside HIPS bead) is

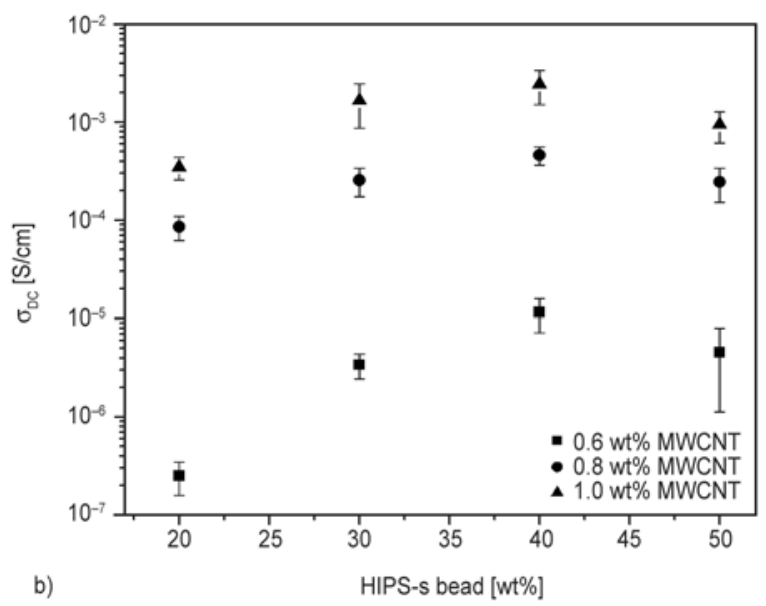

Figure 3. DC Conductivity of HIPS/MWCNT nanocomposites with the weight $\%$ of (a) HIPS bead, and (b) micron-sized HIPS-s bead, in the HIPS matrix at various MWCNT loadings 
directly proportional to the available surface area of the beads, these HIPS-s beads (diameter $\approx 200 \mu \mathrm{m}$ ) with high surface area will influence more diffusion of small molecule from in-situ polymerized region to bead and thus would cause an increment in conductivity. Interestingly, we found that $0.6 \mathrm{wt} \%$ MWCNT and $50 \mathrm{wt} \%$ HIPS-s bead loaded composite shows DC conductivity of $1.37 \cdot 10^{-5} \mathrm{~S} / \mathrm{cm}$, which is much higher than the conductivity $\left(6.43 \cdot 10^{-6} \mathrm{~S} / \mathrm{cm}\right)$ observed in the composite with $50 \mathrm{wt} \%$ HIPS bead with similar MWCNT (0.6 wt \%) loading. When we increase the loading of HIPS-s bead beyond $50 \mathrm{wt} \%$, DC conductivity of nanocomposite starts decreasing. This may be due to the fusing of HIPS-s bead with each other that makes non-conducting matrix phase. The composite with $40 \mathrm{wt} \%$ HIPS-s bead and $0.6 \mathrm{wt} \% \mathrm{CNT}$ loaded nanocomposite showed a DC conductivity of $\approx 2.27 \cdot 10^{-5} \mathrm{~S} / \mathrm{cm}$, on the other hand $60 \mathrm{wt} \%$ HIPS bead loaded composite shows $1.15 \cdot 10^{-6} \mathrm{~S} / \mathrm{cm}$ quite similar range of DC conductivity.

Figure 4 shows the DC conductivity of $60 \mathrm{wt} \%$ HIPS beads containing composite with increasing MWCNT loading. DC conductivity of the composites sharply increases by several orders of magnitude from $10^{-11}$ to $10^{-4} \mathrm{~S} / \mathrm{cm}$ by varying the CNT loading from $0.2-0.6 \mathrm{wt} \%$. This drastic increase in conductivity is well known as percolation phenomena which indicate the formation of the continuous network structure of MWCNT throughout the nanocomposites. While increasing the CNT loading

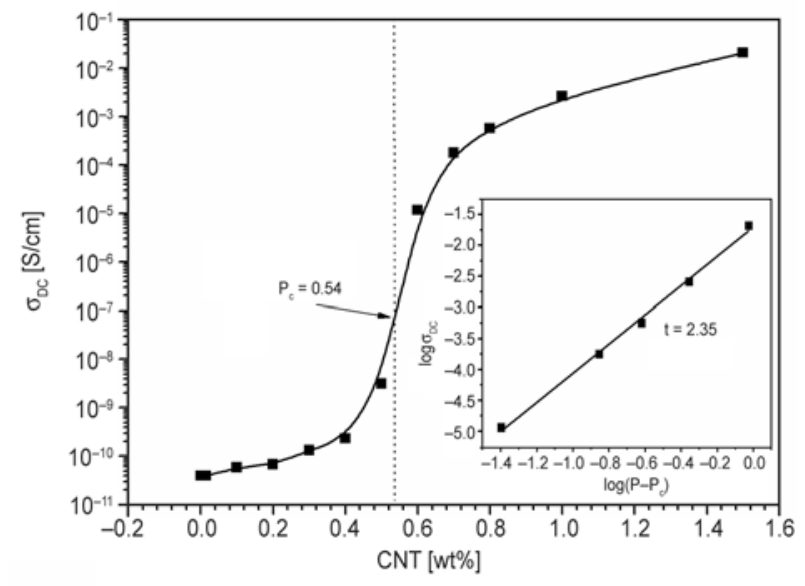

Figure 4. DC Conductivity of HIPS/MWCNT nanocomposites with MWCNT loading at constant $60 \mathrm{wt} \%$ HIPS bead loading. The Inset: log-log plot for $\sigma_{\mathrm{DC}}$ vs $\left(P-P_{\mathrm{c}}\right)$ for the same nanocomposites. The straight line in the inset is a least-square fit to the data using Equation (4) returning the best fit values $P_{\mathrm{c}}=0.54 \%$ and $t=2.35$. beyond $0.6 \mathrm{wt} \%$, conductivity of nanocomposites increases slowly. The conductivity of HIPS/MWCNT nanocomposites with $60 \mathrm{wt} \%$ HIPS bead increased from $1.15 \cdot 10^{-5}$ to $2.06 \cdot 10^{-2} \mathrm{~S} / \mathrm{cm}$ when the CNT loading in the nanocomposites was increased from 0.6 to $1.5 \mathrm{wt} \%$.

In a composite system where the matrix is an insulator and filler is a conducting material as in the case of polymer/CNT nanocomposites, several theories can be predicted for percolation of the system. The most acceptable relation between the DC conductivity, concentration of nanofiller $(P)$ and percolation threshold concentration $\left(P_{\mathrm{c}}\right)$ can be written as the scaling (power) law equation (Equation (5) and (6)). To estimate the $P_{\mathrm{c}}$ value, experimental data of DC conductivity were linear fitted by using scaling law [31, 32]:

$\sigma_{\mathrm{DC}} \propto\left(P-P_{\mathrm{c}}\right)^{\mathrm{t}}$ for $P>P_{\mathrm{c}}$

$\sigma_{\mathrm{DC}} \propto\left(P-P_{\mathrm{c}}\right)^{-\mathrm{s}}$ for $P<P_{\mathrm{c}}$

Where $\sigma_{\mathrm{DC}}$ is the DC conductivity of the nanocomposites, $s$ and $t$ are the critical exponent. Inset of Figure 3 shows the best linear fitted data considering the value of $P_{\mathrm{c}} \approx 0.54 \mathrm{wt} \%$. This value of $P_{\mathrm{c}}$ gives an excellent fit with least error where $P_{\mathrm{c}}$ value varied from 0.2 0.6. In the same Figure (inset of Figure 3), slope of the fitted straight line represents the critical exponent $(t)$ which was found to be $\approx 2.5 \pm 0.13$ and calculated y-intercept is -1.7 . This exponent data give excellent fit and shows agreements with Equation (5) and (6) and resembles extremely low percolation threshold at $0.54 \mathrm{wt} \%$ of CNT in the HIPS matrix. Percolation theory suggests that for three dimensional (3D) percolation network value of the critical exponent $t$, should be greater than 2 . In our case the value of $t \approx 2.5$ well agrees with the theoretical value and indicates the presence of $3 \mathrm{D}$ percolation network over the nanocomposites [33, 34]. According to $3 \mathrm{D}$ percolation theory, the value of the critical exponent lowers than 2 shows the presence of more dead arm in the conducting network. The value of critical exponent not only depends on the type of polymer or CNT but also, on the method of nanocomposites preparation. Kota et al. [35] used two different solvent namely DMF and THF for preparing PS/MWCNT nanocomposites and found two different $t$ values of 1.5 and 1.9, respectively. In the literature there are large vari- 
ances reported for systems containing different polymers such as, $t=1.8$ for epoxy/MWCNT [36], $t=$ 3.8 for polycarbonate/MWCNT [37], $t=2.3$ for PMMA/MWCNT [38] nanocomposites. The critical exponent value mainly depends on the aspect ratio of CNT, carbon purity of CNT, a type of polymer and CNT dispersion method. Out of those factors only dispersion method can be moderate. In our work this extremely ultra-low percolation threshold value indicates excellent dispersion of high aspect ratio MWCNT in the matrix polymer. Balberget et al. [39] proposed a general relationship between the aspect ratio of filler and percolation threshold. This relationship is considered with an assumption that the fillers are randomly distributed and fillers have sticks like structure with a length $(L)$ and diameter $(D)$, and thus represents as shown by Equation (7):

$\frac{L}{D}=\frac{3}{P_{\mathrm{c}}}$

where $P_{\mathrm{c}}$ is the percolation threshold and $L / D$ is the aspect ratio of the filler. By this relation we can estimate the average aspect ratio of CNT bundles. This CNT has a natural tendency to agglomeration and become a bundle like arrangement in the composite. These bundles are responsible for the development of electrical conductivity in the composite. The size of those bundles indicated the dispersion level of the nanofiller in polymer matrix. The average aspect ratio of MWCNT in this study is $150(L=$ $1.3 \mu \mathrm{m}, D=9.5 \mathrm{~nm}$, data given by the manufacturer) that gives the $P_{\mathrm{c}}$ value $\approx 0.02$. However, we found the value of $P_{\mathrm{c}} \approx 0.54$. In our case, the calculated (from Equation (7)) theoretical aspect ratio of CNT bundles

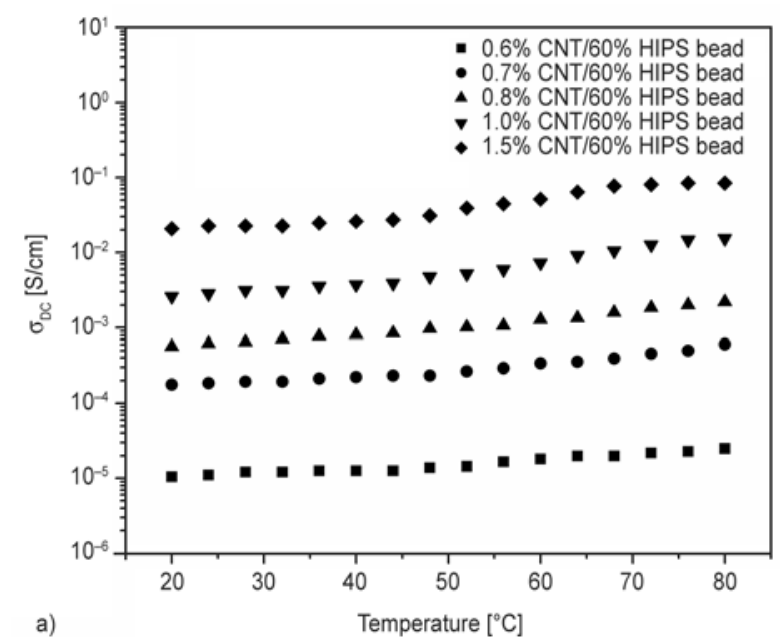

is $\sim 5.66$. This analysis unambiguously shows that the conductivity in the composite is due to MWCNT bundle, and not because of individual CNT. However these bundles also have a high aspect ratio, and thus, tend to reduce the percolation threshold of the nanocomposite.

On the other hand, considering y intercept of fitted line in Figure 4 (Inset), the $100 \mathrm{wt} \%$ loading of filler (extrapolation value of $P \rightarrow 100$ ) gives the DC conductivity value $1.99 \cdot 10^{-2} \mathrm{~S} / \mathrm{cm}$. This value is far lower than the conductivity $(50 \mathrm{~S} / \mathrm{cm})$ expected for the pure MWCNT [40, 41]. A decrease in conductivity of CNT is associated with the tunneling barrier between CNTs. The tunneling barrier is mainly depends on the type of polymer and fabrication process of nanocomposites.

To verify the tunneling as exact mechanism behind the conduction in HIPS/CNT nanocomposites, the temperature dependence behavior of the DC conductivity was studied. Figure 5a depicts the temperature dependence of DC conductivity of the nanocomposites having $P>P_{\mathrm{c}}$ at a temperature range of 20 $80^{\circ} \mathrm{C}$. As observed, the increment in DC conductivity is very less with increase in temperature. A nonmetallic behavior of DC conductivity was evident in the nanocomposites in the investigated temperature range. The Figure 5a also shows the temperature dependence of DC conductivity does not depend on the CNT content, and thus, it can be reasonably assumed that the conduction at room temperature is controlled here by the connectivity of the conductive network. For disordered materials, a theoretical expression can be obtained for tunneling conductivity in the nanocomposites consisting of

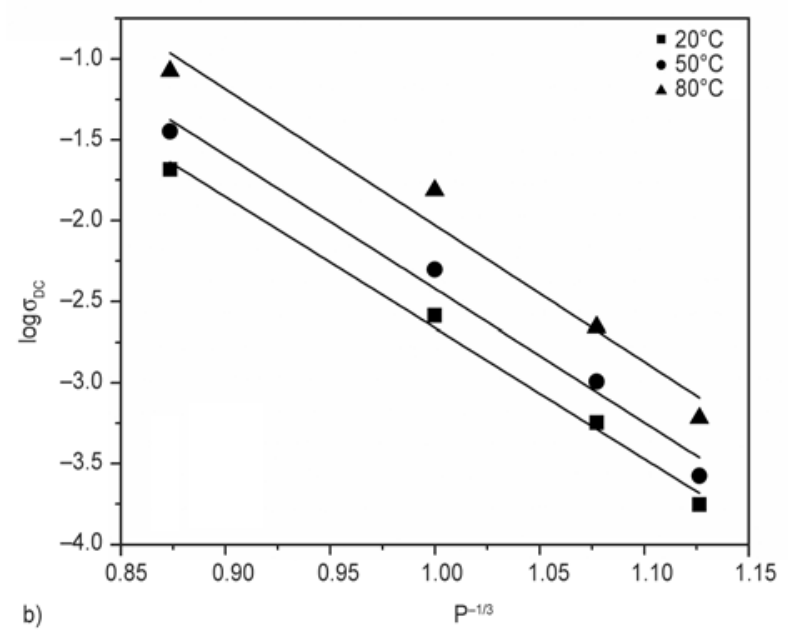

Figure 5. (a) Temperature dependence of DC conductivity of the nanocomposites having $P>P_{\mathrm{c}}$ (b) Linear variation of $\log \sigma_{\mathrm{DC}}$ vs $P^{-1 / 3}$ 
large conducting regions separated by potential barriers. At higher temperature, the thermally activated voltage fluctuations across insulating regions change the effective barrier between CNTs. Sheng [42] suggested the following relationship (Equation (8)) for the temperature dependent conductivity:

$\sigma_{\mathrm{DC}}=\sigma_{0} \exp \left(-\frac{T_{1}}{T+T_{0}}\right)$

where $T_{1}$ is the energy required for an electron to cross the insulating gap between conductive particles aggregates and $T_{0}$ represents the temperature above which the thermally activated conduction over the barrier begins to occur.

Conductivity of nanocomposites assisted with tunneling, is expressed as shown by Equation (9):

$\sigma_{\mathrm{DC}} \propto \exp (-A d)$

where $A$ is tunneling parameter and $d$ is the distance between CNTs. When conducting particles are randomly distributed in insulating matrix, then mean average distance between particles is directly proportional to $P^{-1 / 3}$. Thus, Equation (9) can be written as Equation (10):

$\log \sigma_{\mathrm{DC}} \propto P^{-1 / 3}$

In conducting polymer composites, various researchers have reported tunneling conduction generating from the contacts between conductive clusters is responsible for conductivity $[43,44]$. In our system, the variation in electrical conductivity could be associated with tunneling through a potential barrier of varying height resulting from the thermal fluctuations. A polymer nanocomposites consisting of randomly distributed conducting particles, it can be shown that the mean average distance among particles is proportional to $P^{-1 / 3}$ and also $\log \sigma_{\mathrm{DC}}$ is proportional to $P^{-1 / 3}$. The linear relationship between $\log \sigma_{\mathrm{DC}}$ and $P^{-1 / 3}$ (Figure $5 \mathrm{~b}$ ) is indicative to the fact that tunneling conduction may be present in our samples.

However, it is very difficult to explain very low percolation and high conductivity of nanocomposites, because exact size and morphology of MWCNT bundle is not known. The TEM image revealed that MWCNT are uniformly and randomly dispersed in a polymer matrix and have physical entanglement with each other. There are so many factors which influence the high conductivity of nanocomposites. These experiments show that the reason behind conductivity is not only physical contact between CNT or CNT bundles but also the presence of electron tunneling between them. These results revealed that there are many possible factors which can increase the conductivity of the nanocomposites.

I. The high $L / D$ ratio of MWCNT and MWCNT bundles makes a three dimensional conducting structure throughout the matrix but it is very difficult to know the mean size and aspect ratio of MWCNT bundles.

II. High entanglement and irregular packing of MWCNT lead to a good conducting network. Very high surface area of MWCNT and its boundary increases the probability of electron tunneling between them.

III. High surface area of MWCNT and MWCNT bundles increases the probability of tunneling of electrons which leads to a lower $P_{\mathrm{c}}$ value.

IV. MWCNTs and MWCNT bundles can make physical entanglement with neighboring tubes and bundles, and also presence of high Van der Waals forces between CNTs can hold them together. This contact may be with or without a tunneling barrier which leads to a remarkably low $P_{\mathrm{c}}$ value.

Although the first factor plays the major role in conductivity but it is not itself sufficient, consequently some or all of the other three factors are also essential for lowering the $P_{\mathrm{c}}$ value.

However, in the present work of HIPS/MWCNT nanocomposites, effective CNT concentration in the bulk polymerized HIPS phase is increased by incorporating the HIPS beads that led to a reduction in the inter CNT distance. With the increasing of CNT loading from 0.5 to $1 \mathrm{wt} \%$, the conductivity value of the nanocomposites drastically increases from $3.14 \cdot 10^{-9}$ to $2.59 \cdot 10^{-3} \mathrm{~S} / \mathrm{cm}$. The conductivity of nanocomposites stabilized at around $10^{-3} \mathrm{~S} / \mathrm{cm}$ which to the best of our knowledgeis the highest value of conductivity ever reported for HIPS/MWCNT nanocomposites at this low level of CNT loading with unaligned, unmodified, commercially available MWCNTs of similar qualities (carbon purity, aspect ratio, etc.)

Comparison of electrical conductivity of the HIPS/ MWCNT nanocomposites prepared by our new method with conventional solution blending and melt-mixing method with different weight percent- 


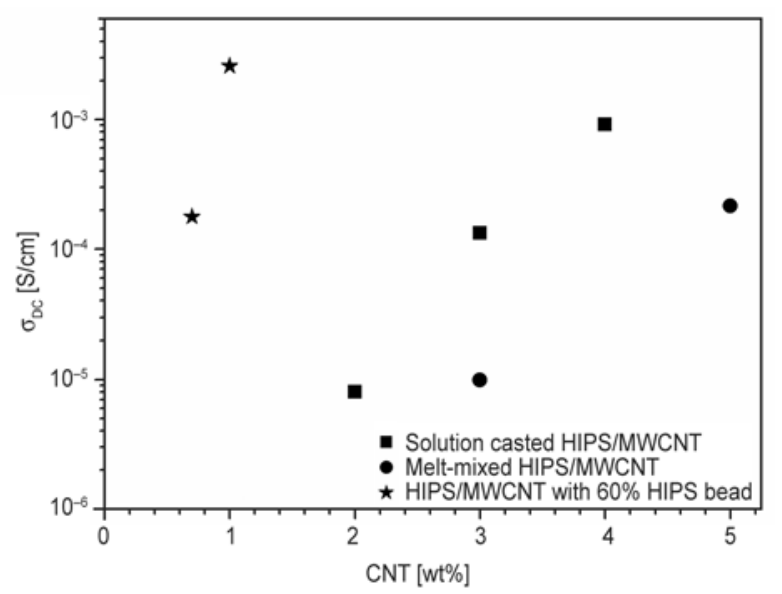

Figure 6. Comparison of the DC conductivity of HIPS/ MWCNT nanocomposites prepared by different methods in our study

age of MWCNT is shown in Figure 6. DC conductivity of solution blended nanocomposites was observed $\approx 8.01 \cdot 10^{-4}$ and $1.32 \cdot 10^{-4} \mathrm{~S} / \mathrm{cm}$ with 2 and $3 \mathrm{wt} \%$ of CNT loadings, respectively. Whereas in our new method similar range of conductivity values of $1.15 \cdot 10^{-5}$ and $5.67 \cdot 10^{-4} \mathrm{~S} / \mathrm{cm}$ was achieved in the nanocomposites even at 0.6 and $0.8 \mathrm{wt} \% \mathrm{CNT}$ loading, respectively. Moreover, the nanocomposites prepared by conventional melt-mixing method shows the DC conductivity of $\approx 9.93 \cdot 10^{-5} \mathrm{~S} / \mathrm{cm}$ at $3 \mathrm{wt} \%$ CNT loading. The similar range of conductivity $\left(\approx 1.15 \cdot 10^{-5} \mathrm{~S} / \mathrm{cm}\right)$ can be obtained with $\approx 5$ times lower CNT loading in the nanocomposite prepared by the proposed method. This very high conductivity of the nanocomposites prepared by the proposed method is due to selective localization of all the CNT in the in situ polymerized HIPS phase in the nanocomposites. Thus, the probability of entanglement between CNTs and tunneling of electrons is expected to increase in comparison to other nanocomposites prepared by conventional methods.

The relationship between AC conductivity and frequency for pure polymer and the nanocomposites containing $0.6 \mathrm{wt} \%$ MWCNT loading with varying weight present of HIPS beads is shown in Figure 7a. As can be seen, the AC conductivity of pure polymer increases with increasing frequency, consistent with the behavior of an insulating material. Surprisingly, increasing the weight present of HIPS beads in the nanocomposites at constant CNTs loading shows a gradual increase in conductivity. Increment of HIPS beads in nanocomposites force the CNTs to concise in a small volume of the nanocomposites that leads to more entanglement between them and results in increasing the conductivity value.

It is observed that the AC conductivity remained constant in plateau region up to a critical frequency $\left(f_{\mathrm{c}}\right)$, beyond which the conductivity of all the nanocomposites increases with the frequency. Critical frequency $\left(f_{\mathrm{c}}\right)$ of the nanocomposites shifted at higher frequencies with increasing weight percent of HIPS beads. Many researchers $[45,46]$ found a similar kind of increment in the $f_{\mathrm{c}}$ with increasing of conducting filler loading whereas in our case same trend of $f_{\mathrm{c}}$ was found at constant CNTs loading with varying HIPS beads loadings. This is due to the increase in effective concentration of the CNT in the nanocomposites with bead content which in turn increases the concentration of CNT in selective region of the in situ polymerized HIPS phase.

Figure $7 \mathrm{~b}$ represents the frequency dependence AC conductivity of the nanocomposites with a variation of CNT loading at a constant concentration of HIPS (60 wt $\%$ ) bead. Compared to the pure HIPS, a higher

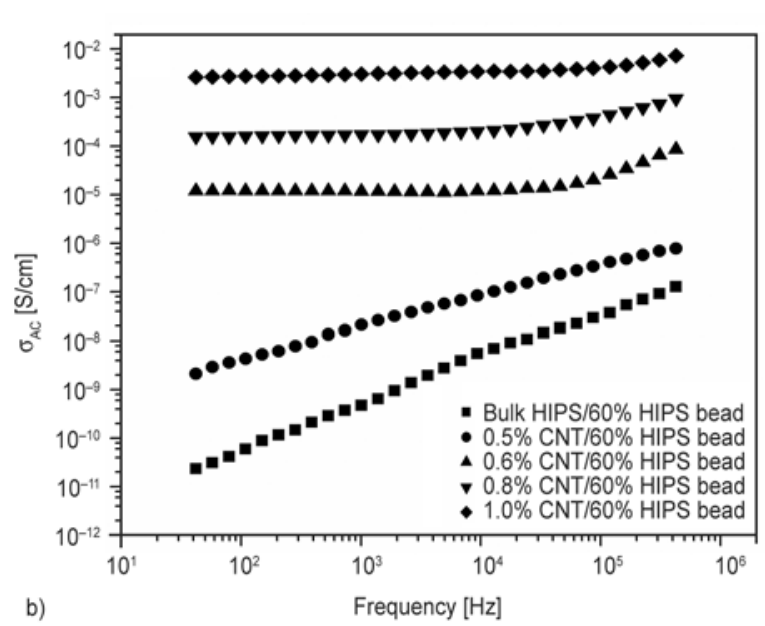

Figure 7. AC conductivity of the HIPS/MWCNT nanocomposites versus frequency at (a) various weight percent of HIPS beads at $0.6 \mathrm{wt} \%$ CNT loading and (b) different MWCNT loadings at constant HIPS bead content 
conductivity is observed in the nanocomposites with increasing $\mathrm{wt} \%$ of CNT loading. With an increase in CNT loading from $0 \sim 0.6 \mathrm{wt} \%$, a sharp increase in conductivity was found in the low frequency region. However, beyond this $(0.6 \mathrm{wt} \%)$ CNT loading, a slow but gradual increase in conductivity was evident with the frequency. Furthermore, the nanocomposites containing CNT greater than $1 \mathrm{wt} \%$ showed almost constant conductivity value throughout the entire frequency range ( $42 \mathrm{~Hz} \sim 5 \mathrm{MHz})$. This is thegeneral behavior of a highly conducting material where the AC conductivity occurs mainly due to the flow of electrons, and not due to the polarization of materials.

The dielectric permittivity $\left(\varepsilon^{\prime}\right)$ determines the ability of a material to store electric potential energy under the influence of an external electric field. Thus, $\varepsilon^{\prime}$ is proportional to the capacitance of the material and alignment of dipoles. Figure $6 \mathrm{a}$ and $6 \mathrm{~b}$ shows the variation of dielectric constant of HIPS/MWCNT nanocomposites at constant frequency $(1 \mathrm{kHz}$ and $1 \mathrm{MHz}$ ) with increasing amount (wt $\%$ ) of HIPS bead at constant ( $0.6 \mathrm{wt} \%)$ CNT loading, and with increasing of CNT at constant ( $60 \mathrm{wt} \%)$ HIPS bead loading, respectively. As can be observed, the dielectric constant of the nanocomposites decreased with increasing frequency in both the cases. The dielectric constant of pure HIPS has a low value than all the nanocomposites and behaves almost independent of frequency.

A decrease in $\varepsilon^{\prime}$ is evident in the composites with increase in frequency from $1 \mathrm{kHz}$ to $1 \mathrm{MHz}$. In dielectric materials, it is generally expected that, the $\varepsilon^{\prime}$ should decrease with increase in the frequency [47]. Potschke et al. [48] studied the dielectric constant of polycarbonate/MWCNT composites above the percolation threshold. They also found similar trends of decreasing of dielectric constant with increasing frequency. At low frequency, accumulated interface charges were more readily redistributed on the applied field direction [49]. However, at higher frequency, the periodic alternation of applied electric field leads to the drastic reduction in the diffusion of dipoles in the field direction and the dipole get less time to orient themselves in the direction of alternating field, resulting in decrease in the values of polarization as well as in the $\varepsilon^{\prime}$ value [50]. In both the cases (Figure $8 \mathrm{a}$ and $8 \mathrm{~b}$ ), dielectric constant of the HIPS/MWCNT nanocomposites increased with increasing amount of HIPS bead as well as with the CNT content. Increase in $\varepsilon^{\prime}$ with effective concentration of MWCNT in HIPS/MWCNT nanocomposite can be explained based on the enhancement of interfacial polarization. It occurs due to the presence of a thin layer of polymer between CNTs or CNT bundles. The degree of interfacial polarization and charge density is very high resulting from the very large conductivity difference between the MWCNT and the insulating polymer matrix. This interfacial polarization is known as the MaxwellWagner-Sillars (MWS) effect [51]. These separated CNTs bundles form, micro capacitors of various length scales [52]. Consequently, the overall capacitance value was increased which resulted in an

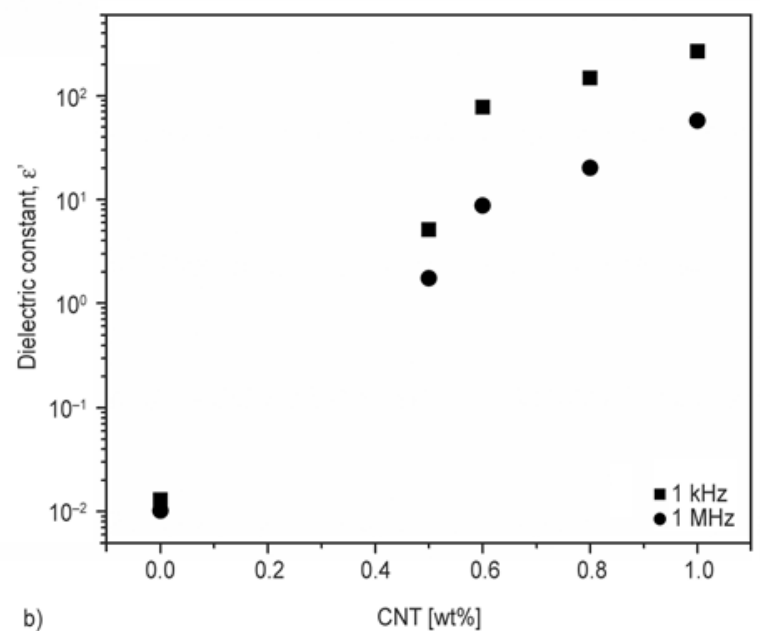

b)

a)

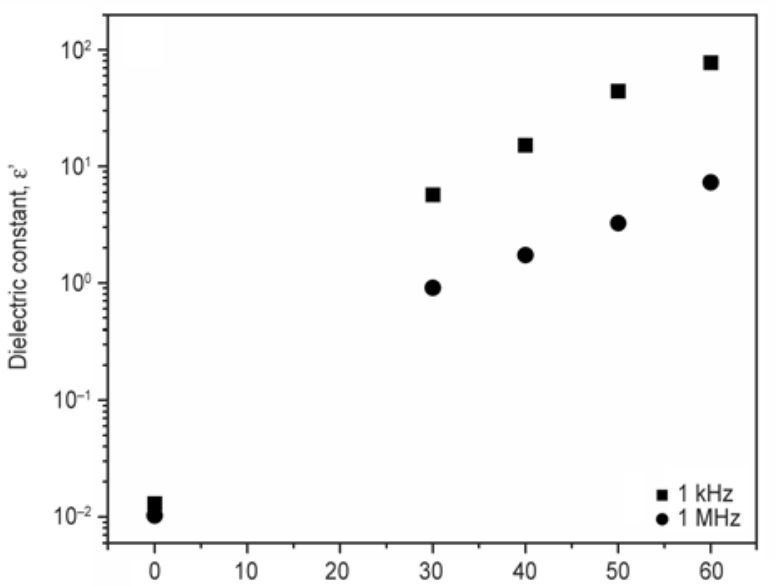

a) HIPS bead [wt\%]

Figure 8. Dielectric constant of HIPS/MWCNT nanocomposites at constant frequency ( $1 \mathrm{kHz}$ and $1 \mathrm{MHz}$ ) (a) with variation of HIPS bead loading at constant $(0.6 \mathrm{wt} \%)$ CNT loading and (b) with variation of CNT loading at constant (60 wt $\%)$ HIPS bead loading 


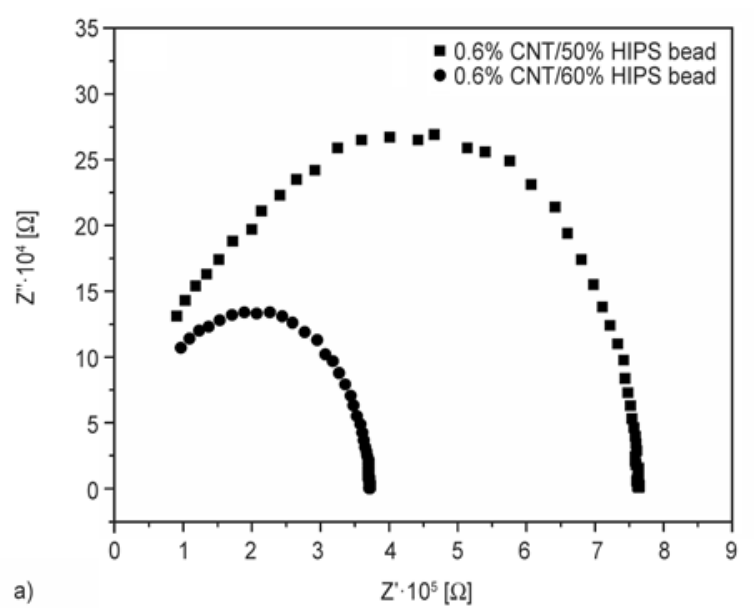

Figure 9. Cole-Cole plots of HIPS/MWCNT nanocomposites bead (50 and $60 \mathrm{wt} \%$ )

increase in the dielectric constant of the nanocomposites.

Figure 9a shows the real $\left(Z^{\prime}\right)$ and imaginary $\left(Z^{\prime \prime}\right)$ components of the complex impedance (Cole-Cole) of the HIPS/MWCNT nanocomposites at $0.6 \mathrm{wt} \%$ MWCNT loading with varying amount of HIPS bead (50 and $60 \mathrm{wt} \%$ ), while Figure $9 \mathrm{~b}$ shows the same plot at $0.8 \mathrm{wt} \%$ MWCNT loading. In Cole-Cole plot for polymer/conducting filler nanocomposites system, the real part of impedance represents bulk resistance $\left(R_{\mathrm{B}}\right)$ and the imaginary part of impedance represents maximum angular frequency value $\left(\omega_{\max }\right)$. The effect of change in real and imaginary part of the impedance of the system can be expressed in terms of the Equation (11):

$\omega_{\max }=\frac{1}{R_{\mathrm{B}} C_{\mathrm{B}}}$

As can be seen, that in the both figure (Figure 9a and 9b) Cole-Cole plot yields nearly perfect semi-circle. The radius of these semi-circles decreased with increasing HIPS beads. These indicate that the conductivity of the nanocomposite increases with the increase in the HIPS beads which are associated with effective concentration of MWCNT in HIPS/ MWCNT nanocomposite. The Cole-Cole plot of nanocomposite indicates that the composite can be demonstrated by a parallel $R C$ network. At higher frequencies, the release of space charges accumulated at the interface between the MWCNT and the polymer matrix occurs, and thus $Z^{\prime}$ values seem to be merged together [53]. All the nanocomposites samples exhibited a decrease in $Z^{\prime}$ with increasing HIPS bead and MWCNT, indicating an increase in DC conductivity.

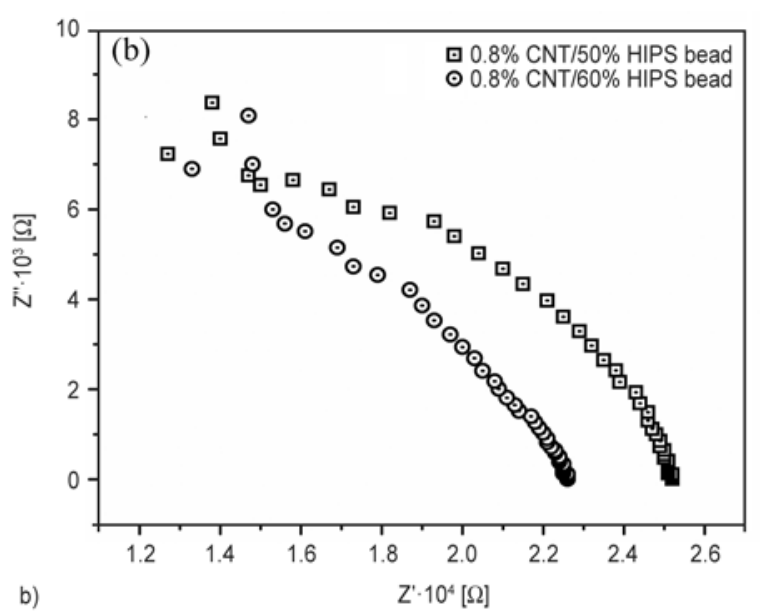

a) $0.6 \mathrm{wt} \%$ (b) $0.8 \mathrm{wt} \%$, MWCNT loading variation of HIPS

\section{Conclusions}

This work demonstrates an easy method for the preparation of HIPS/MWCNT nanocomposites through selective dispersions of MWCNT in the HIPS matrix. A significantly lower value of the percolation threshold of MWCNT was obtained using unmodified and unaligned MWCNT,which is the lowest value ever reported for HIPS/MWCNT nanocomposites system. The incorporation of HIPS bead during the polymerization process acted as 'excluded volume' forcing the MWCNT to disperse selectively in the small region of in-situ copolymerized HIPS phase of the nanocomposites. This sort of selective dispersion of MWCNT in the lower volume of in-situ polymerized phase increased the effective concentration of MWCNT, leading to the percolation threshold to a lower value of $0.54 \mathrm{wt} \%$ of MWCNT. Theoretical studies revealed that the conduction mechanism in the nanocomposites is not only via physical contact between the individual MWCNTs, but also electron tunneling between the neighboring MWCNTs. The polymer coating over individual MWCNT during the bulk polymerization process was indicated from the theoretical approach. The parameters like bead size, bead adding time during copolymerization and bead concentration acted as supreme factors to shift the percolation threshold to an extremely lower value.

\section{References}

[1] Connor M. T., Roy S., Ezquerra T. A., Calleja F. J. B.: Broadband AC conductivity of conductor-polymer composites. Physical Review B, 57, 2286-2294 (1998). DOI: 10.1103/PhysRevB.57.2286 
[2] Foulger S. H.: Electrical properties of composites in the vicinity of the percolation threshold. Journal of Applied Polymer Science, 72, 1573-1582 (1999).

DOI: $10.1002 /(\mathrm{SICI}) 1097-4628(19990620) 72: 12<1573$ $:$ AID-APP10>3.0.CO;2-6

[3] Lozano K., Bonilla-Rios J., Barrera E. V.: A study on nanofiber-reinforced thermoplastic composites (II): Investigation of the mixing rheology and conduction properties. Journal of Applied Polymer Science, 80, 1162-1172 (2001).

DOI: $10.1002 / a p p .1200$

[4] Zois H., Apekis L., Omastová M.: Electrical properties of carbon black-filled polymer composites. Macromolecular Symposia, 170, 249-256 (2001).

DOI: 10.1002/1521-3900(200106)170:1<249::AID-

\section{MASY249>3.0.CO;2-F}

[5] Jäger K-M., McQueen D. H.: Fractal agglomerates and electrical conductivity in carbon black polymer composites. Polymer, 42, 9575-9581 (2001).

DOI: $10.1016 / \mathrm{S} 0032-3861(01) 00478-5$

[6] Kar P., Khatua B. B.: PTCR characteristics of polycarbonate/nickel-coated graphite-based conducting polymeric composites in presence of poly(caprolactone). Polymer Composites, 32, 747-755 (2011).

DOI: $10.1002 /$ pc. 21093

[7] Kar P., Shrivastava N. K., Mallick S., Khatua B. B.: PTCR characteristics of poly(styrene-co-acrylonitrile) copolymer/stainless steel powder composites. Journal of Applied Polymer Science, 124, 607-615 (2012). DOI: 10.1002/app.35002

[8] Shrivastava N. K., Khatua B. B.: Development of electrical conductivity with minimum possible percolation threshold in multi-wall carbon nanotube/polystyrene composites. Carbon, 49, 4571-4579 (2011).

DOI: $10.1016 /$ j.carbon.2011.06.070

[9] Maity S., Shrivastava N. K., Khatua B. B.: Reduction of percolation threshold through double percolation in melt-blended polycarbonate/acrylonitrile butadiene styrene/multiwall carbon nanotubes elastomer nanocomposites. Polymer Composites, 34, 570-579 (2013). DOI: $10.1002 /$ pc. 22462

[10] Spitalsky Z., Tasis D., Papagelis K., Galiotis C.: Carbon nanotube-polymer composites: Chemistry, processing, mechanical and electrical properties. Progress in Polymer Science, 35, 357-401 (2010). DOI: $10.1016 /$ j.progpolymsci.2009.09.003

[11] Moniruzzaman M., Winey K. I.: Polymer nanocomposites containing carbon nanotubes. Macromolecules, 39, 5194-5205 (2006).

DOI: $10.1021 / \mathrm{ma} 060733 \mathrm{p}$

[12] Fiedler B., Gojny F. H., Wichmann M. H. G., Nolte M. C. M., Schulte K.: Fundamental aspects of nano-reinforced composites. Composites Science and Technology, 66, 3115-3125 (2006).

DOI: $10.1016 /$ j.compscitech.2005.01.014
[13] Shrivastava N. K., Kar P., Maity S., Khatua B. B.: A facile route to develop electrical conductivity with minimum possible multi-wall carbon nanotube (MWCNT) loading in poly(methyl methacrylate)/MWCNT nanocomposites. Polymer International, 61, 1683-1692 (2012).

DOI: $10.1002 /$ pi.4263

[14] Mitchell C. A., Bahr J. L., Arepalli S., Tour J. M., Krishnamoorti R.: Dispersion of functionalized carbon nanotubes in polystyrene. Macromolecules, 35, 88258830 (2002).

DOI: $10.1021 / \mathrm{ma} 020890 \mathrm{y}$

[15] Bahr J. L., Tour J. M.: Covalent chemistry of singlewall carbon nanotubes. Journal of Materials Chemistry, 12, 1952-1958 (2002).

DOI: $10.1039 / \mathrm{B} 201013 \mathrm{P}$

[16] Dyke C. A., Tour J. M.: Solvent-free functionalization of carbon nanotubes. Journal of the American Chemical Society, 125, 1156-1157 (2003).

DOI: $10.1021 / \mathrm{ja0289806}$

[17] Jin Z., Pramoda K. P., Xu G., Goh S. H.: Dynamic mechanical behavior of melt-processed multi-walled carbon nanotube/poly(methyl methacrylate) composites. Chemical Physics Letter, 337, 43-47 (2001). DOI: $10.1016 / \mathrm{S} 0009-2614(01) 00186-5$

[18] Ayewah D. O., Davis D. C., Krishnamoorti R., Lagoudas D. C., Sue H. J., Willson M.: A surfactant dispersed SWCNT-polystyrene composite characterized for electrical and mechanical properties. Composites Part A, 41, 842-849 (2010).

DOI: $10.1016 /$ j.compositesa.2010.02.015

[19] McNally T., Pötschke P., Halley P., Murphy M., Martin D., Bell S. E. J., Brennan G. P., Bein D., Lemoine P., Quinn J. P.: Polyethylene multiwalled carbon nanotube composites. Polymer, 46, 8222-8232 (2005).

DOI: 10.1016/j.polymer.2005.06.094

[20] Pötschke P., Bhattacharyya A. R., Janke A.: Carbon nanotube-filled polycarbonate composites produced by melt mixing and their use in blends with polyethylene. Carbon, 42, 965-969 (2004).

DOI: $10.1016 /$ j.carbon.2003.12.001

[21] Manchado M. A. L., Valentini L., Biagiotti J., Kenny J. M.: Thermal and mechanical properties of single-walled carbon nanotubes-polypropylene composites prepared by melt processing. Carbon, 43, 1499-1505 (2005). DOI: $10.1016 /$ j.carbon.2005.01.031

[22] Wanjale S. D., Jog J. P.: Crystallization and phase transformation kinetics of poly(1-butene)/MWCNT nanocomposites. Polymer, 47, 6414-6421 (2006). DOI: $10.1016 /$ j.polymer.2006.07.011

[23] McClory C., Pötschke P., McNally T.: Influence of screw speed on electrical and rheological percolation of melt-mixed high-impact polystyrene/MWCNT nanocomposites. Macromolecular Materials and Engineering, 296, 59-69 (2011). DOI: $10.1002 /$ mame. 201000220 
[24] Lee M., Jeon H., Min B. H., Kim J. H.: Morphology and electrical properties of polymethylmethacrylate/ poly(styrene-co-acrylonitrile)/multi-walled carbon nanotube nanocomposites. Journal of Applied Polymer Science, 121, 743-749 (2011).

DOI: $10.1002 /$ app.33819

[25] Göldel A., Kasaliwal G. R., Pötschke P., Heinrich G.: The kinetics of CNT transfer between immiscible blend phases during melt mixing. Polymer, 53, 411421 (2012). DOI: 10.1016/j.polymer.2011.11.039

[26] Dufresne A., Paillet M., Putaux J. L., Canet R., Carmona F., Delhaes P., Cui S.: Processing and characterization of carbon nanotube/poly(styrene-co-butyl acrylate) nanocomposites. Journal of Materials Science, 37, 3915-3923 (2002).

DOI: 10.1023/A:1019659624567

[27] Singh B. K., Kar P., Shrivastava N. K., Banerjee S., Khatua B. B.: Electrical and mechanical properties of acrylonitrile-butadiene-styrene/multiwall carbon nanotube nanocomposites prepared by melt-blending. Journal of Applied Polymer Science, 124, 3165-3174 (2012).

DOI: $10.1002 / a p p .34948$

[28] Zhao Z., Zheng W., Yu W., Long B.: Electrical conductivity of poly(vinylidene fluoride)/carbon nanotube composites with a spherical substructure. Carbon, 47, 2118-2120 (2009).

DOI: 10.1016/j.carbon.2009.03.043

[29] Mu M., Walker A. M., Torkelson J. M., Winey K. I.: Cellular structures of carbon nanotubes in a polymer matrix improve properties relative to composites with dispersed nanotubes. Polymer, 49, 1332-1337 (2008). DOI: $10.1016 /$ j.polymer.2008.01.036

[30] Liu L., Grunlan J. C.: Clay assisted dispersion of carbon nanotubes in conductive epoxy nanocomposites. Advanced Functional Materials, 17, 2343-2348 (2007). DOI: $10.1002 / \mathrm{adfm} .200600785$

[31] Weber M., Kamal M. R.: Estimation of the volume resistivity of electrically conductive composites. Polymer Composites, 18, 711-725 (1997).

DOI: $10.1002 / p c .10324$

[32] Vavouliotis A., Fiamegou E., Karapappas P., Psarras G. C., Kostopoulos V.: DC and AC conductivity in epoxy resin/multiwall carbon nanotubes percolative system. Polymer Composites, 31, 1874-1880 (2010). DOI: $10.1002 /$ pc.20981

[33] Blighe F. M., Hernandez Y. R., Blau W. J., Coleman J. N.: Observation of percolation-like scaling - far from the percolation threshold - in high volume fraction, high conductivity polymer-nanotube composite films. Advanced Materials, 19, 4443-4447 (2007). DOI: 10.1002/adma.200602912

[34] Alig I., Skipa T., Lellinger D., Pötschke P.: Destruction and formation of a carbon nanotube network in polymer melts: Rheology and conductivity spectroscopy. Polymer, 49, 3524-3532 (2008). DOI: $10.1016 /$ j.polymer.2008.05.037
[35] Kota A. K., Cipriano B. H., Duesterberg M. K., Gershon A. L., Powell D., Raghavan S. R., Bruck H. A.: Electrical and rheological percolation in polystyrene/ MWCNT nanocomposites. Macromolecules, 40, 74007406 (2007). DOI: $10.1021 / \mathrm{ma} 0711792$

[36] Martin C. A., Sandler J. K. W., Shaffer M. S. P., Schwarz M-K., Bauhofer W., Schulte K., Windle A. H.: Formation of percolating networks in multi-wall carbon-nanotube-epoxy composites. Composites Science and Technology, 64, 2309-2316 (2004). DOI: 10.1016/j.compscitech.2004.01.025

[37] Pötschke P., Goad M-A., Alig I., Dudkin S., Lellinger D.: Rheological and dielectrical characterization of melt mixed polycarbonate-multiwalled carbon nanotube composites. Polymer, 45, 8863-8870 (2004). DOI: $10.1016 /$ j.polymer.2004.10.040

[38] Kim H. M., Choi M-S., Joo J., Cho S. J., Yoon H. S.: Complexity in charge transport for multiwalled carbon nanotube and poly(methyl methacrylate) composites. Physical Review B, 74, 54202/1-54200/7 (2006). DOI: 10.1103/PhysRevB.74.054202

[39] Balberg I., Anderson C. H., Alexander S., Wagner N.: Excluded volume and its relation to the onset of percolation. Physical Review B, 30, 3933-3943 (1984). DOI: 10.1103/PhysRevB.30.3933

[40] Fan J., Wan M., Zhu D., Chang B., Pan Z., Xie S.: Synthesis, characterizations, and physical properties of carbon nanotubes coated by conducting polypyrrole. Journal of Applied Polymer Science, 74, 2605-2610 (1999).

DOI: 10.1002/(SICI)1097-4628(19991209)74:11<2605 $\because$ AID-APP6>3.0.CO;2-R

[41] Benoit J-M., Corraze B., Lefrant S., Blau W. J., Bernier P., Chauvet O.: Transport properties of PMMA-carbon nanotubes composites. Synthetic Metals, 121, 12151216 (2001).

DOI: $10.1016 / \mathrm{S} 0379-6779(00) 00838-9$

[42] Sheng P.: Fluctuation-induced tunneling conduction in disordered materials. Physical Review B, 21, 2180 2195 (1980). DOI: 10.1103/PhysRevB.21.2180

[43] Alexander M. G.: Anomalous temperature dependence of the electrical conductivity of carbon-poly(methyl methacrylate) composites. Materials Research Bulletin, 34, 603-611 (1999).

DOI: 10.1016/S0025-5408(99)00043-4

[44] Sichel E. K., Gittelman J. I., Sheng P.: Transport properties of the composite material carbon-poly(vinyl chloride). Physical Review B, 18, 5712-5716 (1978). DOI: 10.1103/PhysRevB.18.5712

[45] Kim Y. J., Shin T. S., Choi H. D., Kwon J. H., Chung Y-C., Yoon H. G.: Electrical conductivity of chemically modified multiwalled carbon nanotube/epoxy composites. Carbon, 43, 23-30 (2005). DOI: $10.1016 /$ j.carbon.2004.08.015 
[46] Barrau S., Demont P., Peigney A., Laurent C., Lacabanne C.: DC and AC conductivity of carbon nanotubes-polyepoxy composites. Macromolecules, 36, 5187-5195 (2003).

DOI: $10.1021 / \mathrm{ma} 021263 \mathrm{~b}$

[47] Sahoo B. P., Naskar K., Tripathy D. K.: Conductive carbon black-filled ethylene acrylic elastomer vulcanizates: Physico-mechanical, thermal, and electrical properties. Journal of Materials Science, 47, 2421-2433 (2012).

DOI: $10.1007 / \mathrm{s} 10853-011-6065-8$

[48] Pötschke P., Dudkin S. M., Alig I.: Dielectric spectroscopy on melt processed polycarbonate-multiwalled carbon nanotube composites. Polymer, 44, 5023-5030 (2003).

DOI: $10.1016 / \mathrm{S} 0032-3861(03) 00451-8$

[49] Psarras G. C., Manolakaki E., Tsangaris G. M.: Electrical relaxations in polymeric particulate composites of epoxy resin and metal particles. Composites Part A: Applied Science and Manufacturing, 33, 375-384 (2002).

DOI: $10.1016 / \mathrm{S} 1359-835 \mathrm{X}(01) 00117-8$
[50] Zhao X., Koos A. A., Chu B. T. T., Johnston C., Grobert N., Grant P. S.: Spray deposited fluoropolymer/multi-walled carbon nanotube composite films with high dielectric permittivity at low percolation threshold. Carbon, 47, 561-569 (2009). DOI: $10.1016 /$ j.carbon.2008.10.042

[51] Sillars R. W.: The behaviour of polar molecules in solid paraffin wax. Proceedings of the Royal Society A, 169, 66-83 (1939). DOI: $10.1098 /$ rspa.1938.0195

[52] Pecharromán C., Moya J. S.: Experimental evidence of a giant capacitance in insulator-conductor composites at the percolation threshold. Advanced Materials, 12, 294-297 (2000).

DOI: 10.1002/(SICI)1521-4095(200002)12:4<294:: AID-ADMA294>3.0.CO;2-D

[53] El Ghanem H. M., Jawad S. A., Al-Saleh M. H., Hussain Y. A., Salah W.: Effect of dc-bias on the dielectric behavior of CNT/ABS nanocomposites. Physica B: Condensed Matter, 418, 41-46 (2013).

DOI: $10.1016 /$ j.physb.2013.02.039 